\title{
Analisis dan Perancangan User Manager pada Mikrotik Router dengan Sistem Pembelian Kredit Voucher
}

\author{
William Frado Pattipeilohy \\ Universitas Budi Luhur \\ Jakarta \\ William_frado@yahoo.com
}

\begin{abstract}
Abstrak-- Pengaksesan internet dengan menggunakan layanan hotspot sudah menjadi gaya hidup saat ini. Mikrotik RouterBoard adalah sebuah board router yang di dalamnya sudah terinstal Mikrotik RouterOS, yaitu sistem operasi berbasis Linux yang didalamnya terdapat fitur layanan hotspot. Pada Mikrotik ini terdapat fitur tambahan yaitu User Manager yang merupakan web interface yang user friendly untuk manajemen hotspot.

Pada penelitian ini, server menggunakan Mikrotik RouterBoard750 dengan sistem operasi Mikrotik RouterOS bawaan versi 3.30 yg kemudian di-upgrade ke versi 4.17. User Manager mengikuti versi yang sama yaitu versi 4.11. Kemudian untuk remote Mikrotik dilakukan dengan menggunakan Winbox.Perhitungan pengaksesan internet dilakukan dengan menggunakan sistem voucher.Voucher dihitung berdasarkan besar quota akses maupun total waktu akses. Jika user ID dan password benar, maka pengaksesan internet dapat dilakukan.Pengguna dapat melakukan login tidak hanya di satu waktu tetapi dapat dilakukan berkali-kali, selagi kredit voucher masih ada.Jika telah mencapai batas kredit, maka akses internet secara otomatis dihentikan oleh sistem.

Penggunaan akses internet ini dapat dilaporkan secara harian, mingguan, bulanan, maupun tahunan.Dengan implementasi billing hotspot ini, penyedia layanan hotspot dapat melakukan manajemen pengaturan dan pengontrolan penggunaan akses internet secara terpusat dan terekaputilasi.
\end{abstract}

Kata Kunci-- Hotspot, Mikrotik, User Manager, Billing, Voucher

\section{PENDAHULUAN}

Jaringan berbasis TCP/IP pada saat ini penggunaannya telah menjadi standar komunikasi dunia. Hampir seluruh komputer di seluruh dunia telah terkoneksi menggunakan jaringan ini. Peralatan-peralatan lain juga telah memanfaatkan infrastruktur jaringan ini untuk proses komunikasinya, seperti IP Telephone dan IP Camera.

Melakukan pengontrolan jarak jauh dapat dilakukan dengan menggunakan 2 buah komputer yang terhubung pada jaringan TCP/IP. Satu komputer sebagai server yang terhubung dengan peralatan yang akan dikontrol dan komputer lain sebagai client. Akan tetapi jika peralatan yang dikontrol hanya empat buah lampu, hal ini dirasa akan sangat tidak efisien dan mahal.

Untuk itu penelitian ini akan merancang serta mengimplementasikan aturan-aturan yang ada di dalam protokol TCP/IP ke dalam suatu embedded system. Sehingga embedded system ini bisa digunakan sebagai pengganti komputer server untuk melakukan pengontrolan jarak jauh. Dibandingkan dengan komputer, harga sebuah embedded system jauh lebih murah dan penggunaan daya listrik jauh lebih terjangkau. Hal ini juga didasari pada semakin berkembangnya peralatan yang berbasis IP. Dengan embedded system ini nantinya setiap peralatan dapat memiliki IP address sehingga dapat dikontrol melalui jaringan berbasis TCP/IP.

Rumusan masalah pada penelitian ini antara lain, yaitu Bagaimana mengatur dengan baik system penggunaan layanan hotspot menggunakan fitur User Manger pada Mikrotik RouterOS dengan system pembelian kredit voucher baik berdasarkan total waktu maupun volum quota akses pengguna layanan internet.Bagaimana pengguna layanan dapat melakukan koneksi internet tidak hanya dalam satu waktu selama kredit voucher masih ada dan masih dalam masa aktif voucher.

Adapun batasan-batasan masalah dalam penelitian ini antara lain:Pada sisi server menggunakan Mikrotik RB750 sebagai router board dengan routerOS upgarade versi 4.11 dan User Manager pada Mikrotik upgrade versi 4.11 sebagai billing klien hotspot.Penelitian ditekankan pada sistem pembayaran penggunaan layanan internet hotspot dengan menggunakan voucher.Kuota dan waktu akses internet akan disesuaikan dengan harga voucher.Lama masa aktif voucher sesuai besar kapasitas akses, semakin besar kapasitas akses semakin lama masa aktif voucher. Apabila masa aktif habis maka tidak dapat digunakan lagi oleh pengguna sekalipun quota maupun waktu akses masih bersisa.Pada server billing hotspot dibuat rekapitulasi laporan penggunaan akses internet berupa laporan harian, mingguan, bulanan dan tahunan. 


\section{TINJAUAN PUSTAKA}

\section{A. Jaringan Komputer Secara Umum}

Jaringan komputer adalah sekelompok komputer otonom yang saling mengguanakan protocol komunikasi melalui media komunikasi sehingga dapat dapat berbagi data, informasi, program aplikasi, dan perangkat keras seperti printer, scanner. CD Driver ataupun hardisk, serta memungkinkan untuk saling berkomunikasi secara elektronik [2].

\section{B. Jaringan Wi-Fi/Hotspot}

Wi-Fi merupakan kependekan dari Wireless Fidelity, yang memiliki pengertian yaitu sekumpulan standar yang digunakan untuk Jaringan Lokal Nirkabel (Wireless Local Area Networks - WLAN) yang didasari pada spesifikasi IEEE 802.11. Standar terbaru dari spesifikasi 802.11a atau b, seperti $802.16 \mathrm{~g}$, saat ini sedang dalam penyusunan, spesifikasi terbaru tersebut menawarkan banyak peningkatan mulai dari luas cakupan yang lebih jauh hingga kecepatan transfernya [1].

Awalnya Wi-Fi ditujukan untuk penggunaan perangkat nirkabel dan jaringan area lokal atau dikenal dengan jaringan LAN. Namun saat ini lebih banyak digunakan untuk mengakses internet. Hal ini memungkinan seseorang dengan komputer dengan kartu nirkabel (wireless card) atau Personal Digital Assistant (PDA) untuk terhubung dengan internet dengan menggunakan titik akses (atau dikenal dengan hotspot) terdekat.

\section{C. $\quad$ Standard Wireless}

Standard wirelessyang digunakan adalah standar tipe 802.11g.Tipe ini memiliki kombinasi kemampuan tipe-tipe sebelumnya.Mengunakan frekuensi $2.4 \mathrm{GHz}$ mampu mentransmisi 54Mbps bahkan dapat mencapai 108Mbps bila terdapat inisial $\mathrm{G}$ atau turbo.Untuk hardware pendukung, 802.11g paling banyak dibuat oleh vendor.Secara teoritis mampu mentranfer data kurang lebih 20Mbit/s atau 4 kali lebih baik dari tipe $b$ dan sedikit lebih lambat dari tipe a.

\section{Sistem Billing}

Setiap bidang usaha kini selalu melakukan transaksi, apalagi bidang-bidang yang selalu melakukan transaksi dalam jumlah besar seperti rumah sakit atau departement store atau bidang usaha yang transaksinya berbentuk abstrak seperti usaha warung internet atau warung game online, dan disinilah sistem billing bekerja. Secara umum sistem billing telah banyak digunakan hampir di semua bidang usaha. Sistem billing paling banyak digunakan di bidang informasi dan telekomunikasi, contohnya sistem billing digunakan oleh PT.TELKOM untuk mencatat transaksi telepon rumah yang dilakukan oleh pelanggan, kemudiansistem billing digunakan beberapa provider mobile phone untuk mencatat transaks pembicaraan antar pelanggannya, dan masih banyak lagi manfaat sistem billing di dunia usaha [5].

\section{E. Radius Server dan Manajemen AAA}

RADIUS (Remote Authentication Dial-In User Service), adalah suatu metode standar (protokol) yang mengatur komunikasi antara NAS (Network Access Server) dengan AAA (Authentication, Authorization, Accounting) serversudah dilengkapi fitur-fitur standar yang dibutuhkan.Dalam hal ini server AAA yang digunakan dapat juga disebut sebagai server RADIUS, dan paket-paket data yang terlibat dalam komunikasi antara keduanya disebut sebagai paket RADIUS [3][4].

Authentication adalah suatu proses dimana user diidentifikasi oleh server AAA sebelum user menggunakan jaringan. Pada proses ini, user meminta hak akses kepada NAS untuk menggunakan suatu jaringan. NAS kemudian menanyakan kepada server AAA apakah user yang bersangkutan berhak untuk menggunakan jaringan atau tidak.Authorization adalah pengalokasian layanan apa saja yang berhak diakses oleh user pada jaringan. Authorization dilakukan ketika user telah dinyatakan berhak untuk menggunakan jaringan.Accounting merupakan proses yang dilakukan oleh NAS dan AAA server yang mencatat semua aktivitas user dalam jaringan, seperti kapan user mulai menggunakan jaringan, kapan user mengakhiri koneksinya dengan jaringan, berapa lama user menggunakan jaringan, berapa banyak data yang diakses user dari jaringan, dan lain sebagainya. Informasi yang diperoleh dariproses accounting disimpan pada AAA server, dan dapat digunakan untuk berbagai keperluan seperti billing, auditing, atau manajemen jaringan.

Ketika NAS menerima permintaan koneksi dari user, NAS akan mengirimkan informasi yang diperolehnya dari user ke server RADIUS. Berdasarkan informasi tersebut, server RADIUS akan mencari dan mencocokkan informasi mengenai usertersebut pada databasenya, baik internal, eksternal, maupun server RADIUS lain.Jika terdapat informasi yang cocok, server RADIUS akan mengizinkan user tersebut untuk menggunakan jaringan. Jika tidak, maka user tersebut akan ditolak. Berdasarkan informasi ini, NAS memutuskan apakah melanjutkan atau memutuskan koneksi dengan user. Selanjutnya, NAS mengirimkan data ke server RADIUS untuk mencatat semua kegiatan yang dilakukan user dalam jaringan. Enkapsulasi terhadapnya. Header LLCmemberitahukan kepada data Link untuk melakukan apa terhadap data yang masuk.Peralatan jaringan yang bekerja pada layer ini adalah SwitchdanBridge.

\section{F. Mikrotik RouterOS}

Mikrotik Router OS ${ }^{\mathrm{TM}}$, merupakan sistem operasi Linux base yang diperuntukkan sebagai network router. Didesain untuk memberikan kemudahan bagi penggunanya.Administrasinya bisa dilakukan melalui Windows Application (WinBox).Selain itu instalasi dapat dilakukan pada standar komputer, Personal Computer (PC). PC yang akan dijadikan router mikrotik pun tidak memerlukan resource yang cukup besar untuk penggunaan standard, misalnya hanya sebagai gateway. Untuk keperluan beban yang 
besar (network yang kompleks, routing yang rumit) disarankan untuk mempertimbangkan pemilihan resource $\mathrm{PC}$ yang memadai [3].

Adapun jenis-jenis mikrotik antara lain yaitu:

- $\quad$ Mikrotik RouterOS yang berbentuk software yang dapat di-download di www.mikrotik.com. Dapat diinstal pada kompuetr rumahan (PC).

- Built-In Hardware Mikrotik dalam bentuk perangkat keras yang khusus dikemas dalam board router yang didalamnya sudah terinstal MikroTik RouterOS.

Dari dua jenis diata terdapat beberapa tipe microtik yang dipergunakan adalah Mikrotik RB750,

\section{G, User Manager}

User Manager Mikrotik merupakan sistem manajemen yang dapat dipergunakan untuk me-manage user sebagai berikut (Fajar, 2007):

- HotSpot users

- $\quad$ PPP (PPtP/PPPoE) users

- $\quad$ DHCP users

- Wireless users

- RouterOS users

Penggunaan User Manager untuk hotspot user sebelumnya paket hotspot dan DHCP server harus sudah terinstal (enable) dan dikonfigurasi terlebih dahulu pada Mikrotik RouterOS. Asumsi pada tulisan ini RouterOS terdiri atas 1 wlan dan 1 ether. Ether sebagai interface yang terhubung ke internet sedangkan wlan sebagai interface yang terhubung ke hotspot klien. IP ether1 192.168.0.40 dan wlan1 dengan IP 172.16.0.1/24. Tampilan halaman login terlihat seperti Gambar 1

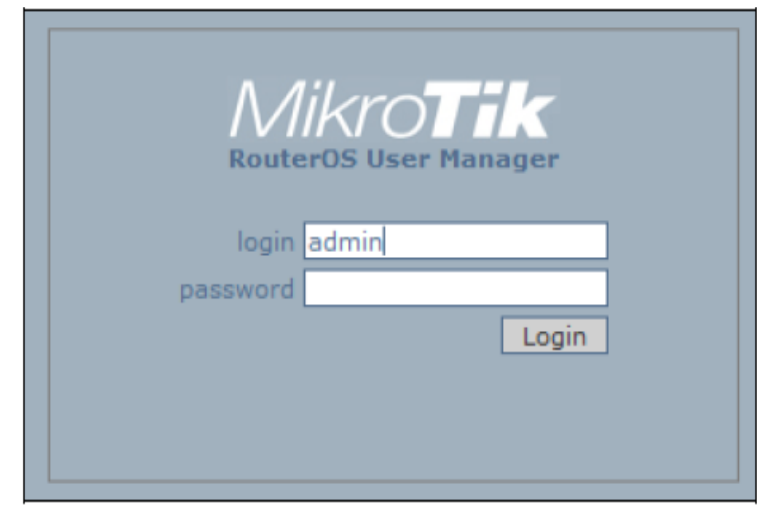

Gambar 1. Halaman login User Manager

Pada saat penelitian ini akan dibuat versi terbaru dari routerOS yaitu routerOS versi 4.11, maka paket User Manager yang akan digunakan juga menggunakan versi 4.11

- Buat pada User Manager nama subscriber:/tool usermanager customer add login="admin" password=123 permissions $=$ owner
- Buat hotspot Router: tool user-manager router add subscriber=admin $\quad$ ipaddress $=172.16 .0 .1 \quad$ sharedsecret $=123456$

- Buat user : untuk hotspot/tool user-manager user add username $=$ fajar password $=123$ subscriber $=$ admin

User Manager adalahweb interface dengan menu-menu berbasis web yang dipergunakan untuk memanage user hotspot. User manager pada Mikrotik disini berfungsi sebagai manajemen AAA, dimana sebelumnya pada Mikrotik diaktifkan fungsi Radius (Fajar, 2008).

Setelah berhasil login User Manager maka akan tampak halaman utama User Manager seperti Gambar 2.

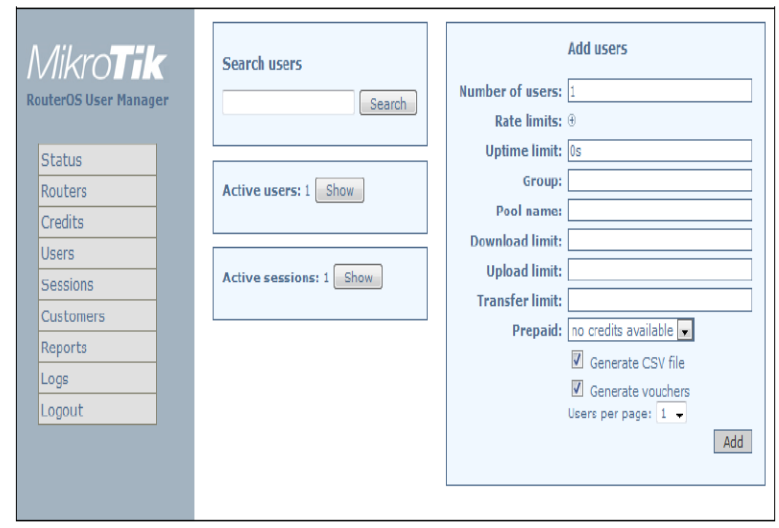

Gambar 2 Tampilan halaman utama User Manager

Fitur yang dimiliki antara lain menambah, mengubah, menghapus user, membuat kredit, melihat session, melihat laporan masing-masing user dan sebagainya. Adapun fungsi pada menu yang terdapat pada User Manager, antara lain:

1) Menu Credit

- Credit merupakan istilah yang digunakan untuk menyatakan berapa lama seorang user diperkenankan untuk mengakses hotspot (Analogi dengan masa aktif voucher pulsa Hanphone).

- Memiliki suatu nama yang Unik dan memiliki harga tertentu

- Lama waktu kredit bisa di ekstend

- Kredit akan mulai berlaku atau dihitung mundur oleh sistem saat pertama kali user login

- Lama credit bisa dinyatakan dalam satu satuan waktu $\operatorname{detik(s),~menit~(m),jam~(h),~hari~(d),~minggu~(w)~dan~}$ seterusnyagin.

2) Menu User

- Digunakan untuk memanage user hotspot, meliputi menambah user baru, menghapus menentukan kredit user, menentukan uptime user, melihat aktifitas dan lain-lain. 
- User name untuk isi namauser, password untuk isi password user yang bersangkutan.

- Uptime limitdiisi dengan waktu yang diijinkan user tersebut bisa menggunakan akses.

- Add Time diisi kredit yang berlaku untuk user tersebut

- Jika uptime limit telah terlampaui maka user tersebut tidak bisa lagi menggunakan akses walaupun kredit masih tersisa. Jika kredit telah terlampaui maka user juga tidak bisa mengakses meskipun uptime limit masih tersisa.

3) Menu User

Menu ini berfungsi untuk membuat customer yang dapat mengakses User Manager berikut hak aksesnya.

\section{4) Menu Report}

Menu ini berfungsi untuk melihat rekapitulasi akses dari setiap user untuk merinci penggunaan akses internet, dimana dapat dibuat laporan harian, mingguan, bulanan, dan tahunan.

\section{METODE PENELITIAN}

Metode penelitian yang digunakan adalah sebagai berikut:

\section{A. Metode Pengumpulan Data}

Dalam hal pengumpulan data, Penulis memilih metode Studi Kepustakaan dan Observasi.

\section{1) Studi Kepustakaan / Literatur}

Yaitu penelitian dengan cara membaca literatur yang berhubungan dengan keamanan komputer serta buku-buku yang mendukung dengan topik yang akan dibahas dalam penelitian ini

\section{2) Observasi}

Yaitu teknik pengumpulan data dengan mengadakan penelitian dan peninjauan langsung terhadap permasalahan yang diambil.

\section{B.Metode Pengujian Perangkat Lunak}

Pengujian adalah sebuah proses terhadap program atau aplikasi untuk menemukan kesalahan dan segala kemungkinan yang akan menimbulkan kesalahan sesuai dengan spesifikasi perangkat lunak yang telah ditentukan sebelum aplikasi tersebut diserahkan kepada customer. Metode pengujian perangkat lunak terbagi tiga yaitu : metode pengujian white box, dan metode pengujian black box.

\section{1) Pengujian Kotak Putih (White Box)}

Pengujian kotak putih adalah pengujian yang dilakukan lebih dekat lagi untuk menguji prosedur-prosedur yang ada. Lintasan lojik yang dilalui oleh setiap bagian prosedur diuji dengan memberikan kondisi atau loop spesifik. Dengan menggunakan metode pengujian kotak putih, perekayasa sistem dapat melakukan beberapa test case :

\section{2) Pengujian Kotak Hitam (Black Box)}

Pengujian kotak hitam adalah pengujian yang dilakukan untuk antarmuka perangkat lunak, pengujian ini dilakukan untuk memperlihatkan bahwa fungsi-fungsi bekerja dengan baik.

\section{.IV. HASIL DAN PEMBAHASAN}

\section{A. Perancangan Topologi Jaringan Hotspot}

Perancangan arsitektur jaringan hotspot secara fisik dapat dilihat seperti Gambar 3.

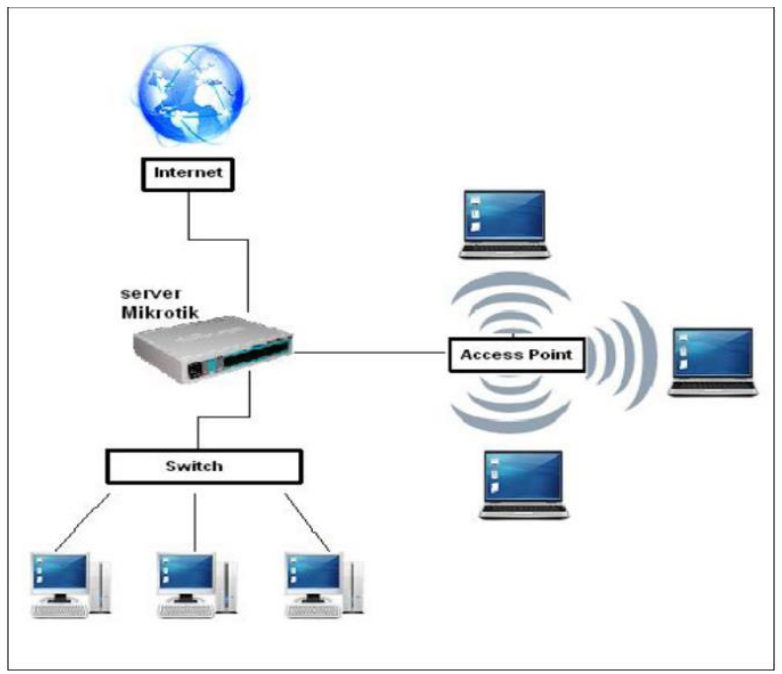

Gambar 3. Skema Rancangan Jaringan Hotspot

Pada gambar terlihat bahwa untuk jaringan lokal digunakan switch untuk menghubungkan antar komputer klien dengan server Mikrotik. Sedangkan pada jaringan hotspot digunakan access point untuk menghubungkan komputer klien ke server Mikrotik yang nantinya akan diteruskan ke jaringan Internet.

Rancangan ini jauh lebih murah apabila dibandingkan menggunakan cisco 871 router dari sisi harga. Berikut perbandingan harga antara menggunakan Mikrotik RB750 dengan menggunakan cisco 871 router. 
Tabel 1. Harga Menggunakan Mikrotik RB750

\begin{tabular}{|c|l|c|}
\hline No & \multicolumn{1}{|c|}{ Spesifikasi Barang } & \multicolumn{2}{|c|}{ Harga } \\
\hline 1 & Mikrotik RB750 & $\mathrm{Rp} 390.000$ \\
\hline 2 & Linksys WAP54G & $\mathrm{Rp} 650.000$ \\
\hline \multicolumn{2}{|c|}{ Total } & $\mathrm{Rp} 1.040 .000$ \\
\hline
\end{tabular}

Tabel 2 Harga Menggunakan Cisco 871-K9

\begin{tabular}{|c|l|l|}
\hline No & Spesifikasi Barang & Harga \\
\hline 1 & Cisco 871-K9 & Rp 2.870.000 \\
\hline 2 & Linksys WAP54G & Rp 650.000 \\
\hline \multicolumn{2}{|c|}{ Total } & Rp 3.520.000 \\
\hline
\end{tabular}

Dari perbandingan di atas dapat dibuktian bahwa perancangan jaringan hotspot lebih murah menggunakan Mikrotik RB750.

\section{B. Perancangan Hardware dan Software}

Perancangan interface billing ini akan menggunakan beberapa perangkatkeras (hardware) dengan spesifikasi sebagai berikut :

1) Satu unit server billing (notebook):

- Intel Core 2 Duo Processor T6670

- Memory 4 GB

- Hardisk $320 \mathrm{~GB}$

2) Mikrotik RB750

3) Access Point Linksys WAP54G ver. 3

4) Kabel UTP

5) Satu unit switch D-Link

6) Satu unit notebook sebagai klien

Kemudian software berikut merupakan aplikasi tambahan yang akan diinstalkan langsung ke dalam Mikrotik, antara lain:
1) Winbox
2) Net Install
3) Paket upgrade router board versi 4.17
4) Paket upgrade User Manager versi 4.17

\section{Proses Pembuatan Billing Hotspot} berikut:

Proses pembuatan aplikasi ini melalui tahapan-tahapan

1) Instalasi Winbox

2) Upgrade Mikrotik RouterOS dari versi 3.30 ke versi 4.17

3) Instalasi User Manager versi 4.17

4) Konfigurasi dasar Mikrotik
Jurnal SISFOKOM, Volume 05, Nomor 01, Maret 2016

5) Konfigurasi hotspot Mirotik

6) Desain manajemen voucher hotspot dengan User Manager

7) Desain hak akses pengguna (customer) User Manager

8) Uji coba implementasi

\section{Diagram Alir User Manager Oleh Administrator}

Pada sisi admin, segala aturan dalam manajemen penggunaan hotspot oleh klien akan dilakukan pada User Manager Mikrotik. Berikut diagram alir proses pengaksesan User Manager oleh admin.

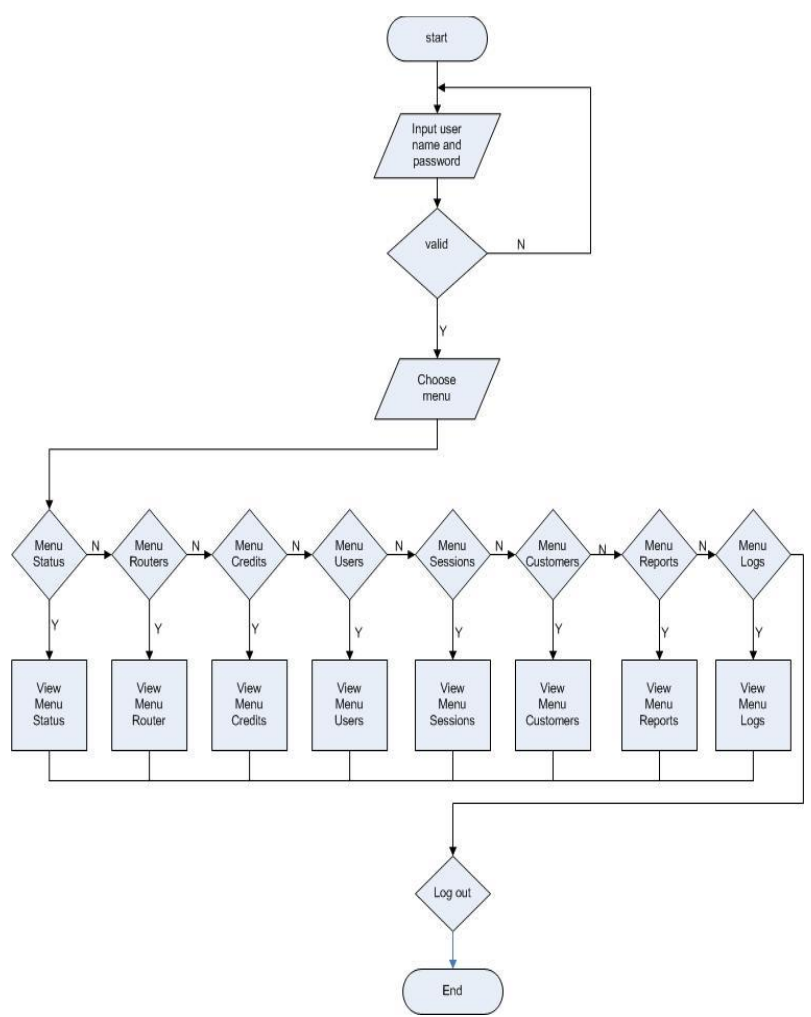

Gambar 4. Diagram alir User Manager oleh admin

\section{E. Rancangan Konfigurasi Pembuatan Hotspot Mikrotik}

Pada aplikasi ini dilakukan konfigurasi dasar Mikrotik dan setelah itu dilakukan konfigurasi hotspot Mikrotik.

1) Konfigurasi dasar Mikrotik, menu-menu yang akan dikonfigurasi antara lain:

- Interfaces, dimana pada menu ini akan diberikan nama pada masing-masing ether disesuaikan dengan fungsinya agar mudah dalam mengingat pengkonfigurasian. Penamaannya antara lain:

- $\quad$ IP $\square$ Addresses

- Menu ini digunakan untuk memberikan IP Address masing-masing interface

- $\quad$ IP $\square$ DHCP Client 
- Menu ini digunakan mikrotik untuk menerima IP Address dari modem ADSL.

- $\quad$ IP $\square$ Routes

- Menu ini digunakan untuk mengkonfigurasi agar semua range IP akan diroutingkan pada IP Route-nya dimana disini diberikan IP Route: 118.136.130.1/24 sebagai gateway.

- $\quad$ IP $\square$ Firewall

- Pada menu ini firewall NAT pada Mikrotik diaktifkan, dimana NAT berfungsi untuk meneruskan paket dari IP lokal ke IP publik (fungsi gateway router).

- IP $\square \square$ Pool

- Menu ini digunakan untuk menentukan range IP yang akan diberikan ke user.

- $\quad$ IP $\square \square$ DHCP Server

- Pada menu Name diisi nama yang sesuai agar mudah diingat yaitu "landhcp", dan "hotspot-dhcp". lease time di-setting $3 \mathrm{~d}$ yang artinya klien diberi waktu 3 hari.

- $\quad$ IP $\square \square$ DNS

DNS diisi sesuai dengan DNS yang didapatkan dari ISP (Internet Service Provider)

2) Konfigurasi hotspot Mikrotik

- IP $\square \square$ Hotspot

- Pada menu ini diberikan nama pada profil server hotspot yaitu "Hotspot", kemudian pada menu ini dihubungkan dengan IP Pool hotspot

- Kemudian pada tab Radius, diaktifkan piihan Use Radius karena pada aplikasi ini menggunakan aplikasi tambahan yaitu User Manager.

- Kemudian konfigurasi hotspot user profile digunakan untuk menyimpan data user yang akan dibuatkan rule profilnya.

- Radius

Pada menu ini fungsi Radius pada hotspot diaktifkan. Radius disini sebagaiserver untuk manajemen AAA yang dilakukan pada User Manager

\section{PENUTUP}

\section{A. Kesimpulan}

Setelah melakukan uji coba terhadap penelitian ini didapatkan kesimpulan, antara lain:

- Pengaturan dan manajemen penggunaan layanan hotspot menggunakan fitur User Manager pada
Mikrotik RouterOS dengan sistem pembelian kredit voucher ini berjalan sesuai dengan hasil yang ingin dicapai.

- Pada sisi server, admin dapat melakukan perhitungan besar kapasitas pengaksesan internet dan perhitungan pendapatan keuangan secara tepat dan akurat.

- Pada sisi pengguna, pengaksesan internet dapat dilakukan tidak hanya di satu waktu selama kredit voucher masih ada.

\section{B. Saran}

Pada penelitian ini diuraikan beberapa saran yang diharapkan dapat melengkapi kesempurnaan dari penelitian ini, antara lain:

- Sebaiknya ditambahkan rancangan bentuk fisik voucher dimana terdapat keterangan secara tertulis informasi link bagi pengguna untuk dapat melihat status sisa kredit voucher yang dimiliki.

- Sebaiknya dilakukan backup data pada Mikrotik secara berkala.

- Sebaiknya dilakukan uji coba user aktif sebanyak 200 sekaligus, sebagai pembuktian maksimal user aktif hotspot yang bisa digunakan pada Mikrotik RB750.

\section{DAFTAR PUSTAKA}

[1] Alam, M.A.J., 2008, Wifi, Hotspot, LAN, dan Sharing Internet, Penerbit Elex Media Komputindo, Jakarta.

[2] Fajar, G.M., 2008, Web Interface User Manager Mikrotik

http://fajar.uii.net.id/index.php?option $=$ com_content $\& t$ ask=view\&id=29\&Itemid $=1,1$ Februari 2008

[3] Handriyanto, D.F., 2009, Kajian Penggunaan Mikrotik Router OS ${ }^{\mathrm{TM}}$ Sebagai Router pada Jaringan Komputer, http://www.unsri.ac.id/upload/arsip/Kajian

Penggunaan Mikrotik OS Sebagai Router.pdf, diakses 08 Maret 2010.

[4] Herlambang, M.L. dan Catur, L.A., 2008, Menguasai Router Masa Depan Menggunakan Mikrotik RouterOS, Penerbit ANDI, Yogyakarta.

[5] Nurriza, P.S., 2008, Manajemen Authentication, Authorization dan Accounting serta penerapan Quota Time User pada Wi-Fi, Skripsi, Fakultas Matematika dan Ilmu Pengetahuan Alam, Universitas Gadjah Mada, Yogyakarta 